\title{
Ocultismo, esoterismo y pseudociencia; disparates en torno al megalitismo
}

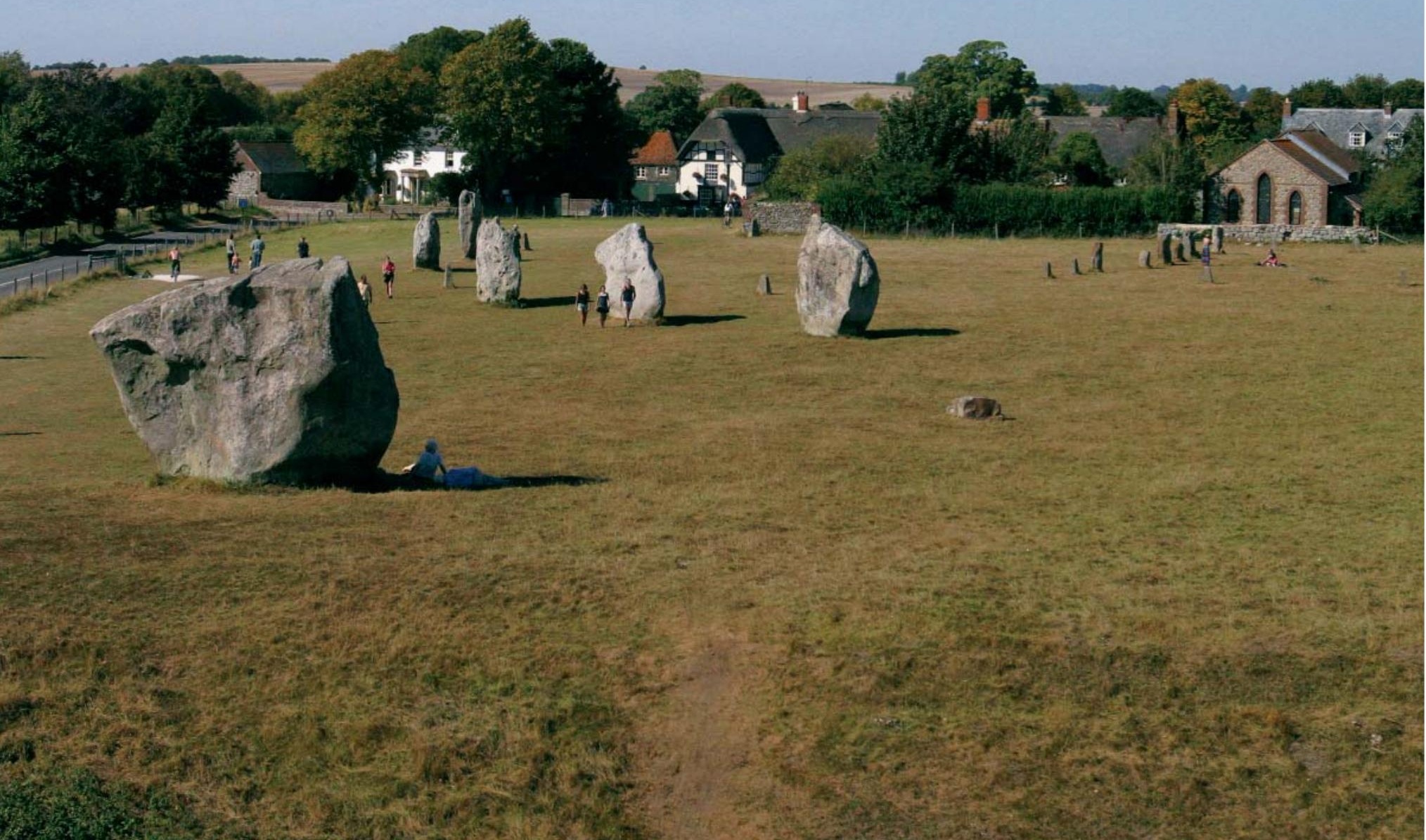


Desde que a mediados del siglo XIX la arqueología prehistórica comenzara a transformar de forma irreversible la visión que el ser humano tenía de su propia posición en el tiempo y el universo, demoliendo las interpretaciones bíblicas de la antigüedad del mundo y nuestro origen como especie, ciencia e irracionalidad han librado una lucha constante. Conforme a los métodos y teorías de la arqueología se hicieron más robustos y precisos a lo largo del siglo XX, las interpretaciones religiosas, míticas y acientíficas del pasado fueron quedando en una situación de creciente marginalidad, al menos en apariencia. Una de las paradojas de la ciencia arqueológica actual es que determinadas nociones y teorías completamente acientíficas siguen teniendo un considerable arraigo en según qué colectivos. La controversia habida en los EEUU sobre la llamada teoría del diseño inteligente como alternativa a la teoría científica de la evolución biológica humana es un buen ejemplo de la vitalidad que determinadas explicaciones totalmente acientíficas del pasado de la humanidad pueden mostrar en nuestros días. Una nutrida literatura ha tratado de este tema. En el caso de la Arqueología es posible destacar dos grandes síntesis de referencia: F. Harrold y R. Eve (Editores), Cult Archaeology and Creationism: Understanding Pseudo-scientific Beliefs About the Past, (lowa City, University of lowa Press, 1987) y K Feder, Frauds, Myths, and Mysteries: Science and Pseudoscience in Archaeology (Mountain View, Mayfield, 1999).

El megalitismo es precisamente uno de los dominios de la arqueología prehistórica que de forma más activa y regular ha atraído a los aficionados a las explicaciones esotéricas e irracionales. Los temas de estudio abordados por la pseudociencia en relación con el megalitismo son diversos e incluyen desde la brujería, el espiritismo o la muerte hasta la existencia de vida extraterrestre, la vida en el más allá o la telequinesia. En esta breve nota realizaremos un rápido repaso de algunas de las cuestiones básicas planteadas desde el esoterismo y la pseudociencia en relación con el megalitismo. Este examen es importante, ya que la medida en que las explicaciones irracionales se extienden o penetran en distintos sectores de la sociedad es proporcional al fracaso de la comunidad científica en explicar y hacer llegar al público el conocimiento científico establecido.

Uno de los temas favoritos de las visiones esotéricas del megalitismo es la participación de seres no humanos en la construcción de megalitos. En la tradición folclórica europea de origen (al menos) medieval, los mitos y leyendas populares ya conectaron con frecuencia a estos monumentos con razas de gigantes, un hecho que ha quedado reflejado en la actualidad en la toponimia de numerosos megalitos, como explica la profesora María Dolores Gordón Peral en este mismo volumen. ¿Por qué no habría sido capaz el ser humano de construir estos monumentos? Los monumentos megalíticos están a veces construidos con bloques de piedra de excepcional tamaño que, en determinados casos, fueron traídos desde lejanas canteras. Algunos de estos ortostatos pesan decenas de toneladas. La mayor parte de las aproximaciones acientíficas y pseudocientíficas al megalitismo que proliferan en numerosos sitios de Internet consideran que las sociedades prehistóricas habrían carecido de la tecnología, los conocimientos y la capacidad de organización necesarias para erigir esos grandes monumentos. La falta de útiles adecuados no haría posible el trabajo de bloques de piedra de gran tamaño y de materiales de gran dureza (pórfido, granito, etc.). El supuesto desconocimiento de la plomada y del nivel ha sido asimismo esgrimido para cuestionar la autoría humana de grandes monumentos prehistóricos y antiguos, ya que algunos de estos monumentos son simétricos y tienen unas proporciones geométricas homogéneas. Tampoco el transporte de la materia prima habría sido posible con los medios técnicos disponibles, ya que se desconoce cómo las comunidades constructoras de estos monumentos pudieron mover bloques de este peso a través de decenas de kilómetros. Finalmente, se da por supuesto que las orientaciones astronómicas (lunares, solares o estelares) de este tipo de monumentos sólo pueden 

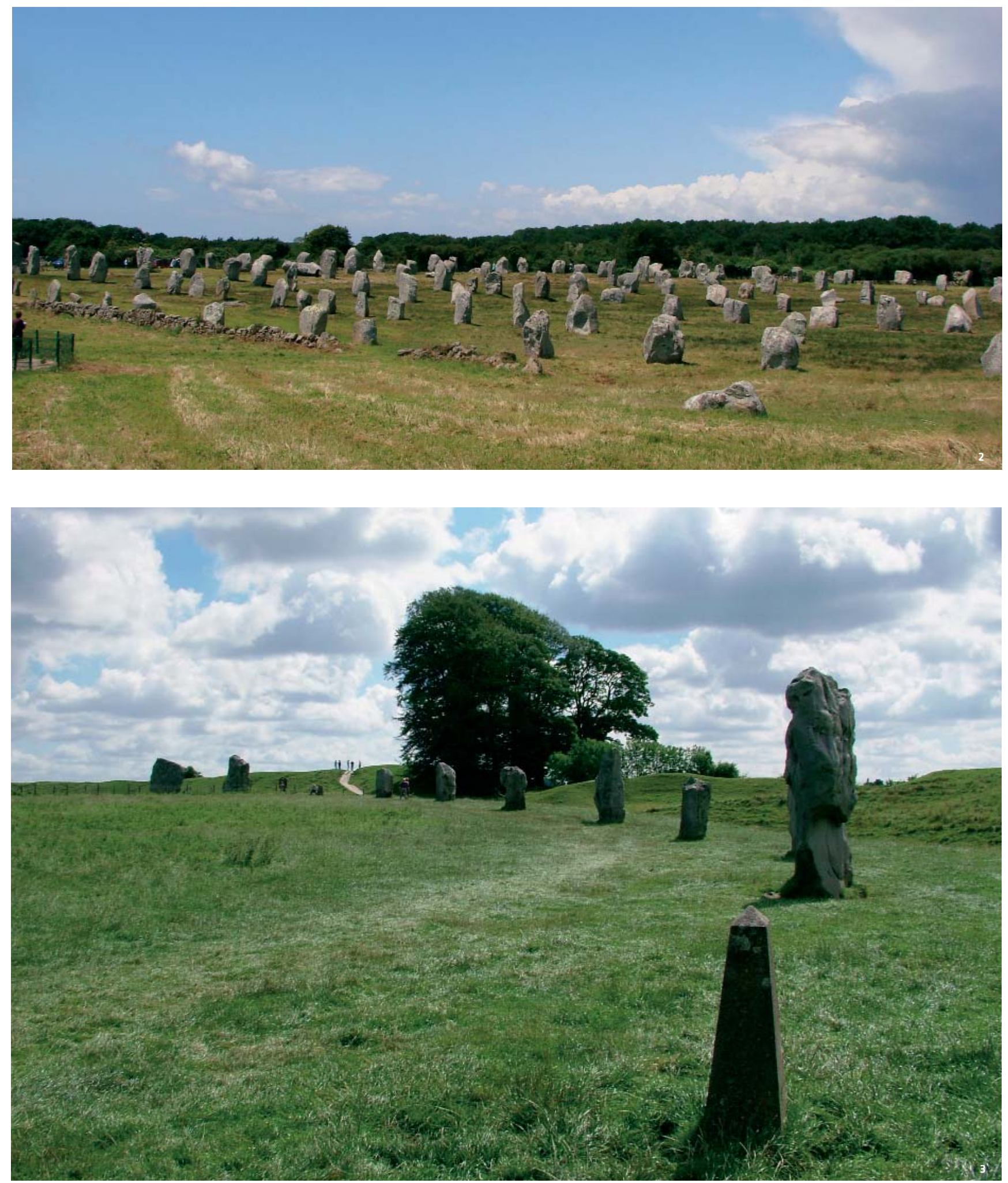
deberse a la existencia de unos conocimientos astronómicos superiores que no estaban al alcance de las comunidades humanas del pasado.

¿Si no construyeron los seres humanos estos monumentos entonces quién lo hizo? Las respuestas dadas por la pseudociencia a esta pregunta son variadas. Algunas propuestas argumentan que los monumentos megalíticos fueron construidos por seres extraterrestres (mientras, es de suponer, nuestros antepasados contemplaban atónitos la ejecución de las obras). Aquellos que creen que la mitología griega es una parte real de la historia del ser humano piensan que los megalitos fueron construidos por hiperbóreos (habitantes inmortales que según la mitología griega habitaban más allá del Bóreas, la Tracia griega), gigantes, titanes, atlantes o alguna civilización desaparecida del mundo, lo que explicaría por qué el megalitismo es un fenómeno global. Por el contrario, en el norte de Europa ha arraigado la noción popular de que estos monumentos fueron construidos por druidas celtas.

Sin duda, entre seres míticos gigantescos, poderosos druidas y extraterrestres, la partida por la autoría de la construcción de ciertos monumentos prehistóricos la ganan estos últimos. En las propuestas esotéricas, ciertos megalitos se usaron como señalizaciones de navegación para posibles naves extraterrestres, como por ejemplo las alienaciones megalíticas de Carnac. Esta misma idea ha sido tradicionalmente empleada para explicar otros monumentos prehistóricos únicos, como por ejemplo los geoglifos de América del Sur, de los cuales el más conocido es el sitio de Nazca (Perú). Por su dificultad, perfección y tamaño sólo habrían podido ser construidos por civilizaciones extraterrestres. Esta hipótesis ha sido formulada repetidamente por los amigos de la pseudociencia, de tal manera que el planeta estaría entero lleno de señalizaciones extraterrestres. Otra hipótesis frecuente es la que considera que ciertos monumentos megalíticos, como por ejemplo Stonehenge, fueron lugares de reunión amistosa entre los extraterrestres y nuestros antepasados ${ }^{1}$. En estos sitios es donde, según la pseudociencia, se intercambiaron ideas y objetos entre los visitantes espaciales y nuestros antepasados prehistóricos. Por el contrario, otros consideran que los monumentos megalíticos fueron empleados para señalar líneas telúricas que dividen el mundo y donde se captaría la energía natural de la tierra a través del campo magnético-terrestre². Estos monumentos serían lugares de sacrificios humanos satánicos o druídicos, razón por la cual hay enterramientos en el interior de algunos megalitos. Esta es una de las explicaciones favoritas de los llamados crop circles (marcas en cultivos) que aparecen con frecuencia en la región meridional inglesa de Wiltshire, donde se encuentra una de las mayores concentraciones de sitios megalíticos de Europa (incluyendo por ejemplo Stonehenge y Avebury). Según otras hipótesis algunos monumentos megalíticos habrían sido lugares de teletransportación que habrían permitido ir a otras dimensiones y otros puntos de la Tierra?
Aunque disparatadas y a veces divertidas, las teorías esotéricas y acientíficas sobre los megalitos y otros monumentos prehistóricos parten de una serie de premisas de fuerte carga ideológica, y no son tan inocentes como en un primer momento pudiera creerse. Entre las premisas generalmente asumidas destacan el racismo (eurocentrismo que presupone la inferioridad de culturas y sociedades no europeas) y el presentismo (superioridad de la sociedad actual frente a otros modelos sociales del pasado). Las poblaciones salvajes y primitivas pre-industriales y pre-capitalistas habrían carecido de los conocimientos y de las capacidades organizativas necesarias para levantar tan impresionantes y hermosos monumentos, por lo cual debieron requerir la ayuda de otros seres venidos de otros planetas. Desgraciadamente, las hipótesis pseudocientíficas tienen bastante difusión en medios de comunicación de fácil acceso como Internet, en forma de discursos poco o nada rigurosos, cuyo tema principal es el morbo por lo (teóricamente) oculto y misterioso y la negación o ignorancia de los hechos científicamente demostrados, con lo cual las citadas premisas subyacentes se difunden de forma solapada. A la vista del debate abierto en los Estados Unidos de América con la teoría del diseño inteligente no parece que se deba minusvalorar la importancia del fenómeno. La popularidad que ha alcanzado en nuestro país un reciente programa televisivo dedicado al periodismo de lo desconocido, donde temas arqueológicos que no tienen nada de misterioso acaban inevitablemente deslizándose hacia el terreno de lo esotérico ${ }^{4}$ demuestra que la arqueología científica tiene una permanente responsabilidad en contrarrestar la influencia y extensión de supercherías que solo aportan a los ciudadanos ignorancia y confusión sobre temas de gran calado, trátese de la evolución humana, las primeras construcciones monumentales o cualesquiera otros.

\section{Notas}

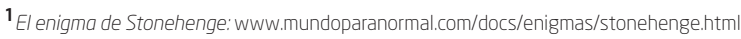

2 El enigma de los megalitos: www.nuevaacropolis.es/NuestraCultura/Simbolismo/ megalitos.htm

${ }^{3}$ Stonehenge. Piedras misteriosas: www.todoleyendas.com/leyendas/Misterios_sin_resolver/ STONEHENGE_Piedras_Misteriosas.php

4 Descubren el templo más antiguo de América: www.ikerjimenez.com/noticias/temploperu/index.html 